Revista de

Contabilidade e

Organizações

www.rco.usp.br
DOI: http://dx.doi.org/10.11606/rco.v10i28.121940
Journal of

Accounting and

Organizations www.rco.usp.br

\title{
A inflação está controlada e não gera impacto nas decisões empresariais. Será?
}

\author{
Zilton Bartolomeu Martins, ; Marisa Luciana Schvabe de Morais ${ }^{\mathrm{a}}$; Helena Wollinger \\ Janypher Marcela Inácio Soares ${ }^{\mathrm{a}}$ \\ ${ }^{a}$ Universidade do Vale do Itajai
}

\section{Informações do Artigo}

Histórico do Artigo

Recebido: 14 de outubro de 2016

Aceito: 09 de janeiro de 2017

\section{Palavras-chave:}

Correção Monetária.

Inflação.

Tomada de Decisão.

Demonstrações Contábeis.

\begin{abstract}
Resumo
Este caso para ensino apresenta uma situação na qual o leitor é levado a refletir sobre o impacto da inflação nas Demonstrações Contábeis. O personagem central do caso em questão é Antônio Morais, um empresário de sucesso, que ao adquirir uma empresa de médio porte, logo tratou de "conhecer" seu novo empreendimento, iniciando com análises detalhadas nas Demonstrações Contábeis, assim como reuniões pontuais com o departamento contábil para esclarecimentos adicionais. Antônio entendia que havia espaço para expandir ainda mais seu novo negócio, mas para isso, precisava de informações seguras que subsidiassem suas decisões. O gestor, decide então, contratar uma Auditoria Independente para analisar as Demonstrações Contábeis da empresa, e recebe um relatório preliminar do Auditor, afirmando não contemplarem, por meio da correção monetária, os efeitos da perda de poder de compra da moeda do país (inflação). O caso busca propiciar uma reflexão quanto aos impactos da inflação nas Demonstrações Contábeis, promovendo assim a oportunidade de explorar conceitos e correlacioná-los com a prática. Este trabalho pode ser utilizado nos cursos de graduação em Administração e Ciências Contábeis, especificamente nas disciplinas de Contabilidade Societária, Análise das Demonstrações Contábeis e Administração Financeira.
\end{abstract}

Copyright $($ C) 2016 FEA-RP/USP. Todos os direitos reservados

\section{INTRODUÇÃO}

Tomar decisões no âmbito empresarial, por si só, já se configura como uma tarefa delicada. A partir de decisões do presente é que o futuro de uma empresa vai se delineando. A tomada de decisão com uma base sólida de informações - embora não assegure resultados necessariamente positivos - certamente, dão ao gestor mais segurança no processo decisório.

Esta é a percepção do empresário Antônio Morais, que sempre buscou pautar suas decisões tomando por referência informações precisas e confiáveis. Contar com um corpo funcional que trabalhe com este mesmo direcionamento tende a tornar a tarefa menos árdua e, por isso, Antônio também vê neste aspecto outro fator determinante nos seus negócios.

Seus empreendimentos - até então exitosos - possivelmente sejam resultado (também) destas posturas. Se o conjunto de informações não for suficientemente preciso e confiável, é razoável depreender que as decisões tomadas a partir destas informações possam ser prejudicadas. Outro fator que sempre preocupa Antônio é a inflação, em outras palavras, o aumento generalizado de preços. Pois, por ser um homem de negócios e ter vivenciado momentos conturbados da economia brasileira, sabe que esta pode corroer o poder de compra do consumidor, impactando assim, tanto nas entradas quanto nas saídas de recursos da empresa.

Antônio Morais se depara - neste caso - com uma situação onde as informações colhidas (especificamente informações de ordem contábil) não dão a ele segurança para suas eventuais decisões. Corrigir o problema refazendo as informações levando em conta a inflação do período - é então o seu ponto de partida e, paralelo a isso, ele precisa se assegurar que as informações vindouras possam lhe dar a segurança que deseja e precisa.

Autor Correspondente: Tel (48) 3285-4449

E-mail: ziltonmartins@univali.br (Z. B. Martins); marisal@univali.br (M. L. S. Morais); helena_wollinger@hotmail.com (H. Wollinger);

janypher@univali.br (J. M. Inácio Soares).

Universidade do Vale do Itajaí - Rua João Coan, 400 - Universitário, Biguaçu, SC, CEP: 88.161-064, Brasil 
Mas, e se, para isto, for necessária outra decisão mais imediata? Se já num primeiro momento - ao assumir seu novo empreendimento - Antônio não recebe informações que reflitam a realidade do seu negócio? Deve ele manter ou substituir os responsáveis pela geração destas informações? Além desta decisão, outras dúvidas permeiam os pensamentos de Antônio: a possível diferença de valores não reconhecidos nas Demonstrações Contábeis influenciariam a tomada de decisão para a nova empresa? E se não bastasse tudo isso, a crise política e econômica do país também pode afetar os rumos do empreendimento?

\section{O CENÁRIO}

Antônio Morais sempre se mostrou um empresário de visão! Desde muito cedo tomava decisões de forma racional, sempre deixando suas emoções de lado, o que lhe dava consciência que precisaria concentrar seus esforços - e recursos - em negócios que pudessem representar um bom potencial de retorno.

O curso superior em Administração lhe auxiliou no desenvolvimento de competências e habilidades que contribuíram para a gestão eficiente das empresas que fundou. Seu primeiro projeto no "mundo dos negócios" teve o providencial aporte de recursos da família, mas, era do seu conhecimento, que se tratava de um fato isolado, não restando a possibilidade - no caso de insucesso - de um novo aporte. Portanto, os resultados colhidos - fossem bons ou ruins - seriam de sua inteira responsabilidade e, mais do que isso, determinantes para os rumos profissionais do jovem administrador.

Este primeiro empreendimento - uma empresa do ramo de calçados, denominada Shoes - se mostrou um negócio bastante promissor. Como consequência, seis anos após sua constituição, Antônio Morais - então com 28 anos - já era um empresário de razoável sucesso.

Seu segundo projeto, dois anos mais tarde, foi a criação e administração de uma clínica veterinária, denominada Charme Dog, concebida originalmente para dar condições a sua esposa (na época, recém-formada no Curso de Medicina Veterinária) de se inserir também no mercado de trabalho. Os recursos para este segundo projeto foram oriundos dos bons resultados colhidos a partir do crescimento e expansão da Shoes.

Duas décadas separaram este momento do atual. Hoje com 48 anos, Antônio Morais, muito bem sucedido em ambas as empresas, fazia seu mais arrojado negócio: a aquisição de uma empresa de médio porte - em funcionamento há 18 anos - do ramo de revenda de veículos, e que possui como denominação social Driving Comércio de Veículos Ltda. O negócio - dado ao volume expressivo de recursos envolvidos - foi maturado por um bom período de tempo. Inúmeras foram as análises e projeções realizadas e inúmeras foram as etapas de negociações.

O cenário econômico do país não se mostrava favorável: a inflação anual atingindo patamares de mais de $10 \%$, retração na grande maioria dos setores, queda na produção industrial e a volatilidade do mercado financeiro, indicavam a necessidade de muita cautela em negociações deste porte. No que diz respeito às expectativas, estas também não eram favoráveis. O conturbado cenário político apontava que, neste ano, a economia iria encolher em torno de 4\% e o índice de confiança do consumidor estava em queda. Ou seja, prudência nos negócios seria fundamental para Antônio.

A negociação se consolidou em 31 de março de 2016, e o investimento por parte de Antônio foi oriundo basicamente de três fontes: $70 \%$ do montante resultou da venda da Shoes para Guilherme Rodrigues (um primo de segundo grau), $15 \%$ do montante foi oriundo de reservas financeiras acumuladas pelo empresário, e os $15 \%$ restantes advindos de capital de terceiros (empréstimo de médio prazo com juros bem negociados). Restava, pois, empreender bem - uma vez mais - e fazer da Driving um sucesso!

\section{A SITUAÇÃO DA DRIVING NO MOMENTO DA AQUISIÇÃO}

A empresa, embora não apresentasse resultados insatisfatórios, precisava, de pronto, ser "repensada". Antônio entendia que havia potencial para auferir resultados ainda melhores, e também espaço para expandir ainda mais seu novo negócio. 
O faturamento líquido da empresa - sem os tributos incidentes sobre a receita - nos últimos cinco anos variou entre $\mathrm{R} \$ 7.925 .000,00$ e $\mathrm{R} \$ 14.050 .000,00$ e o patrimônio total ao fim do ano de 2015 atingia a cifra de $\mathrm{R} \$$ 12.499.000,00.

O quadro funcional contava com 40 colaboradores, distribuído em três departamentos. O departamento de vendas concentrava o maior número (22 pessoas), 15 estavam lotados na área administrativa (gerência, subgerência e auxiliares) e o departamento contábil contava com outros três colaboradores.

Por entender ser importante uma gestão adequada do patrimônio, assim como um controle eficiente e eficaz da situação econômico-financeira da entidade, o empresário destinou especial atenção às informações trazidas pela equipe da área contábil, com o objetivo de subsidiar possíveis e diferentes decisões que estariam por vir.

A equipe de Contabilidade da referida empresa era composta por um Contador - responsável pela elaboração das Demonstrações Contábeis - que atuava na companhia desde a sua criação (18 anos) e dois assistentes com mais de 8 anos de trabalho cada.

As Demonstrações Contábeis foram objeto de análises detalhadas por parte do novo gestor. Reuniões pontuais foram realizadas com o departamento contábil para esclarecimentos das informações contidas nestas. Sendo assim, os Balanços Patrimoniais dos últimos 5 anos são apresentados no Quadro 1.

\begin{tabular}{|c|c|c|c|c|c|}
\hline \multicolumn{6}{|c|}{ DRIVING COMÉRCIO DE VEÍCULOS LTDA } \\
\hline \multicolumn{6}{|c|}{ BALANÇOS PATRIMONIAIS DOS ÚLTIMOS 5 ANOS (Em milhares de reais) } \\
\hline & 2015 & 2014 & 2013 & 2012 & 2011 \\
\hline ATIVO & 12.499 & 12.402 & 11.803 & 11.800 & 9.166 \\
\hline ATIVO CIRCULANTE & 9.654 & 9.260 & 9.329 & 10.465 & 7.992 \\
\hline CAIXA E EQUIVALENTES DE CAIXA & 5.780 & 5.459 & 7.278 & 5.098 & 4.954 \\
\hline CLIENTES & 2.644 & 2.785 & 975 & 4.321 & 2.355 \\
\hline OUTROS CRÉDITOS & 586 & 568 & 417 & 432 & 309 \\
\hline ESTOQUES & 610 & 388 & 558 & 585 & 358 \\
\hline DESPESAS PAGAS ANTECIPADAMENTE & 34 & 60 & 101 & 29 & 16 \\
\hline ATIVO NÃO CIRCULANTE & 2.845 & 3.142 & 2.474 & 1.335 & 1.174 \\
\hline IMOBILIZADO & 4.050 & 4.021 & 3.287 & 2.071 & 1.719 \\
\hline BENS EM OPERAÇÃO & 4.050 & 4.021 & 3.287 & 2.071 & 1.719 \\
\hline (-) DEPREC. E AMORT. ACUMULADAS & $(1.205)$ & $(879)$ & $(813)$ & (736) & $(545)$ \\
\hline DEPRECIAÇÃO ACUMULADA & $(1.205)$ & $(879)$ & $(813)$ & $(736)$ & $(545)$ \\
\hline PASSIVO & 12.499 & 12.402 & 11.803 & 11.800 & 9.166 \\
\hline PASSIVO CIRCULANTE & 1.578 & 1.612 & 1.275 & 1.477 & 647 \\
\hline EMPRÉSTIMOS E FINANCIAMENTOS & - & 2 & 13 & 23 & 39 \\
\hline FORNECEDORES & 293 & 240 & 256 & 370 & 175 \\
\hline OBRIGAÇÕES TRABALHISTAS & 459 & 469 & 357 & 346 & 164 \\
\hline OBRIGAÇÕES FISCAIS & 821 & 896 & 642 & 730 & 265 \\
\hline OUTRAS OBRIGAÇÕES & 5 & 5 & 7 & 8 & 4 \\
\hline PATRIMÔNIO LÍQUIDO & 10.921 & 10.790 & 10.528 & 10.323 & 8.519 \\
\hline CAPITAL SOCIAL & 5.000 & 5.000 & 5.000 & 400 & 400 \\
\hline RESERVAS DE LUCRO & 5.921 & 5.790 & 5.528 & 9.923 & 8.119 \\
\hline
\end{tabular}

Quadro 1: Balanços Patrimoniais da empresa

Fonte: Elaborado pelos autores

Da mesma forma, as Demonstrações de Resultado dos últimos 5 anos são exibidas no Quadro 2 a seguir. 


\begin{tabular}{|c|c|c|c|c|c|}
\hline \multicolumn{6}{|c|}{ DRIVING COMÉRCIO DE VEÍCULOS LTDA } \\
\hline \multicolumn{6}{|c|}{ DEMONSTRAÇÕES DE RESULTADO DOS ÚLTIMOS 5 ANOS (Em milhares de reais) } \\
\hline & 2015 & 2014 & 2013 & 2012 & 2011 \\
\hline (=) RECEITA OPERACIONAL LÍQUIDA & 7.925 & 11.024 & 9.044 & 14.050 & 8.624 \\
\hline (-) CUSTOS DAS MERCADORIAS VENDIDAS & $(5.096)$ & $(6.893)$ & $(5.599)$ & $(7.741)$ & (5.136) \\
\hline (=) LUCRO OPERACIONAL BRUTO & 2.829 & 4.131 & 3.445 & 6.309 & 3.488 \\
\hline (-) DESPESAS/RECEITAS OPERACIONAIS & $(3.083)$ & $(3.854)$ & $(3.337)$ & $(3.908)$ & (3.015) \\
\hline (-) DESPESAS COMERCIAIS & $(1.356)$ & $(1.795)$ & $(1.495)$ & $(1.755)$ & (1.306) \\
\hline (-) DESPESAS ADMINISTRATIVAS & $(1.692)$ & $(1.998)$ & $(1.804)$ & $(2.086)$ & $(1.676)$ \\
\hline (-) OUTRAS DESPESAS OPERACIONAIS & (43) & (76) & (57) & (93) & (35) \\
\hline (+) OUTRAS RECEITAS OPERACIONAIS & 8 & 15 & 19 & 26 & 2 \\
\hline $\begin{array}{c}(=) \text { RESULTADO ANTES DO RESULTADO } \\
\text { FINANCEIRO }\end{array}$ & (254) & 277 & 108 & 2.401 & 473 \\
\hline (-) DESPESAS FINANCEIRAS & (93) & (46) & (19) & (23) & (13) \\
\hline (+) RECEITAS FINANCEIRAS & 527 & 505 & 597 & 678 & 307 \\
\hline $\begin{array}{c}(=) \text { RESULTADO ANTES DOS TRIBUTOS } \\
\text { SOBRE O LUCRO }\end{array}$ & 180 & 736 & 686 & 3.056 & 767 \\
\hline (-) TRIBUTOS SOBRE O LUCRO & (49) & (238) & (221) & $(1.027)$ & (249) \\
\hline (=) RESULTADO LÍQUIDO DO EXERCÍCIO & 131 & 498 & 465 & 2.029 & 518 \\
\hline
\end{tabular}

Quadro 2: Demonstrações de Resultado da empresa

Fonte: Elaborado pelos autores

Ainda que munido das Demonstrações Contábeis e de esclarecimentos adicionais prestados pelo Contador, Antônio Morais entendeu que - neste momento tão embrionário da gestão da Driving - a contratação de uma Auditoria Independente poderia ser prudente, trazendo um olhar mais depurado das referidas Demonstrações, e também isento, por não possuir vínculo ou subordinação com a empresa auditada.

A ideia, portanto, seria - tão somente - aumentar o grau de confiança nas Demonstrações Contábeis por parte do usuário. É relevante ressaltar que as informações de ordem contábil sempre foram importantes para Antônio Morais. Mesmo nas empresas de menor porte que administrou anteriormente, sempre buscou nestas informações - seja pelas Demonstrações Contábeis em si, seja pelas análises possíveis a partir delas - subsídios para suas decisões.

Antônio sempre foi um estudioso de temas contábeis, em especial, das questões fiscais e tributárias que afetavam tão diretamente seus negócios. No entanto, tinha o entendimento que todo esse conjunto de informações que poderiam servir a ele como base sólida para a sua gestão, precisariam vir de um profissional da área. Por isso, mesmo quando não tinha um departamento específico de contabilidade em suas empresas - Shoes e Charme Dog - recorria com frequência a um Contador terceirizado (que também é auditor contábil) que o atendia, para que este pudesse "alimentá-lo" com o máximo de informações.

\section{O RELATÓRIO PRELIMINAR}

Antônio tinha clareza de que, o auditor, ao revisar as Demonstrações Contábeis, o sistema de controles internos e o sistema contábil (ou outros sistemas), poderia comunicá-lo apropriadamente das deficiências eventualmente detectadas, e que - dada a sua relevância - devessem merecer sua atenção como gestor.

O auditor contratado por Antônio Morais fez todo o trabalho de planejamento e execução do serviço de auditoria e, antes de concluí-lo, pôde - com base no trabalho realizado até então - emitir um relatório preliminar que expressa sua opinião sobre as Demonstrações Contábeis, e que tem por finalidade contribuir com a condução ordenada dos negócios da empresa. Ressalta-se que este ainda não é o parecer emitido pelo auditor, e sim, um 
documento que antecipa possíveis “problemas” nas Demonstrações Contábeis, uma vez que Antônio tem pressa para receber estes resultados.

Nesta situação específica, o empresário recebe o relatório preliminar do auditor afirmando que as Demonstrações contábeis da Driving não apresentavam adequadamente a posição patrimonial e financeira da companhia, indicando - dentre outros pontos - que as Demonstrações Contábeis não contemplavam os efeitos da perda de poder de compra da moeda do país (inflação), sendo estas demonstrações elaboradas, equivocadamente, tão somente com base no Custo Histórico e não com base, por exemplo, no Curso Histórico Corrigido, o que, invariavelmente, provocaria distorções na situação patrimonial e financeira.

Destacou também que outras formas e/ou critérios de avaliação e mensuração dos ativos e passivos deveriam ser observadas, tais como, Ajuste a Valor Presente (regulamentado pela NBC TG 12), Valor Justo (NBC TG 46), Valor Recuperável Líquido (NBC TG 16), dentre outras.

No que se refere, pontualmente, a ausência de atualização dos componentes patrimoniais em razão da inflação, o auditor fez constar no relatório, uma tabela divulgada pelo Banco Central Brasileiro (BACEN) na qual informava o percentual de inflação acumulado nos últimos cinco anos, que é medido por meio do Índice de Preços ao Consumidor Amplo (IPCA) por ser considerado o indicador oficial da inflação. Os percentuais são apresentados conforme Tabela 1.

Tabela 1. Percentuais de inflação acumulado nos últimos 5 anos

\begin{tabular}{cc}
\hline Anos & Percentual Acumulado \\
\hline 2011 & $6,50 \%$ \\
2011 a 2012 & $12,71 \%$ \\
2011 a 2013 & $19,37 \%$ \\
2011 a 2014 & $27,02 \%$ \\
2011 a 2015 & $40,58 \%$ \\
\hline
\end{tabular}

Fonte: Banco Central do Brasil (2016)

Dado este contexto, Antônio Morais entendia ser necessário agora, mensurar os impactos causados nas Demonstrações Contábeis, em função dessa não conformidade, e obter as informações efetivamente corretas, até porque, algumas decisões poderiam estar baseadas em índices contábeis e, a atual composição do patrimônio da empresa (sem atualização monetária) poderia provocar distorções relevantes na interpretação dos mesmos.

\section{O IMPACTO CONTÁBIL}

Após o contato com o auditor e, ciente de toda a situação, Antônio não parava de pensar a respeito das Demonstrações Contábeis. Considerando que o Brasil é um país historicamente inflacionário, é facilmente perceptível - ainda que para um leigo em economia ou em contabilidade como Antônio - que desprezar os efeitos da inflação sobre valores históricos registrados provocaria informações não condizentes com o valor real desses registros no momento presente.

A perda de poder de compra da moeda - sentida cotidianamente num ambiente de inflação - certamente não estaria refletida adequadamente nas Demonstrações Contábeis se desprezada a atualização monetária dos ativos e passivos.

Basta imaginar, por exemplo, o registro de um bem adquirido há cinco anos - a custo histórico - estar constando no Balanço Patrimonial da empresa pelo seu valor original. Ora, é fácil depreender que aquele valor originalmente registrado, não estará refletido adequadamente, cinco anos depois, se não tiver sido atualizado. Ademais, a atualização monetária implica exatamente na "manutenção" dos valores originais ao longo do tempo.

Antônio lembrou-se que, durante muito tempo, ouvia dizer coisas do tipo: "a atualização monetária não é mais permitida ou exigida" ou "o Fisco não permite este procedimento desde 1996" e estas considerações o levavam a crer que, de fato, o procedimento não deveria ser feito. Ledo engano! Bastaria uma leitura breve 
das normatizações - especialmente aquelas emanadas pelo Conselho Federal de Contabilidade e que regulam a profissão contábil - para se verificar que a prática é absolutamente necessária.

Independente dos percentuais de inflação que se fizer uso (espera-se, obviamente, no mínimo, a utilização do índice oficial divulgado pelo Governo Federal) não é difícil vislumbrar o quão distorcidos estarão os elementos patrimoniais sem a sua atualização ao longo dos anos.

Diante da informação recebida do auditor - da não conformidade das Demonstrações - e, com o objetivo de verificar (ainda que parcialmente) os impactos da não utilização deste procedimento (atualização monetária), Antônio Morais, pensa na possibilidade de entrar em contato com o Contador que lhe atendeu durante muitos anos para solicitar que fossem reelaborados o Balanço Patrimonial e a Demonstração do Resultado da empresa para o período de cinco anos anteriores e assim, ser possível analisar, pontualmente, o impacto da não adoção da correção monetária do Balanço Patrimonial.

\section{A CONSTATAÇÃO E A DECISÃo}

O Brasil é um país que possui, historicamente, grande volatilidade na economia. E Antônio sabe disso! Nascido em 1968, durante sua juventude vivenciou momentos como a ditadura, as Diretas Já e a hiperinflação. Durante os anos de 1985 e 1994 o país viveu um momento muito delicado, remarcações de preços, escassez de produtos, impeachment, dentre vários outros problemas. Falando especificamente da inflação, bastaria lembrar do ano de 1993 onde ela ultrapassou o patamar de $2.000 \%$ !

Antônio tinha a clara percepção de que atualmente a economia está melhor, mais sólida e com taxas bem menores de inflação. Porém, se analisado o período 2014, 2015 e 2016, por exemplo, também se poderia constatar uma retomada da inflação, e isto precisaria ser levado em consideração para as futuras análises das informações contábeis.

Ciente que o procedimento que asseguraria Demonstrações Contábeis devidamente atualizadas não havia sido feito, Antônio Morais, entendeu ser oportuno (antes de tomar qualquer decisão) questionar a equipe do departamento contábil (mais pontualmente o Contador) os motivos que o levaram a desconsiderar um aspecto tão relevante para a representação adequada do patrimônio.

Convocou-o para uma reunião que seria realizada ainda na semana em curso. A convocação feita pelo novo gestor deixou o Contador estado de apreensão. Ele - o Contador - tinha consciência que, na medida do possível, vinha desempenhando um bom trabalho. Mas, também tinha consciência que na gestão anterior dificilmente era acionado e que, quando isso acontecia, via de regra, não se exigiu dele nada além de posições relacionadas a questões fiscais e tributárias que eram decorrentes, basicamente, da extrema preocupação do gestor anterior em pagar menos impostos.

Não conseguia sequer recordar-se de uma única ocasião em que fora chamado para participar de reuniões mais "estratégicas" da empresa. Às 09 horas da manhã do dia definido, estavam frente a frente o empresário e o Contador (Sr. Jorge Farias). Antônio Morais, ciente da máxima de que "tempo é dinheiro", objetivamente questionou:

Sr. Jorge, creio não precisaremos repassar aqui nenhum referencial teórico sobre economia para que possamos concordar que vivemos num país inflacionário, não? Então, admitindo que isto é ponto pacifico, gostaria que, por favor, você me esclarecesse porque, ao longo destes anos todos, as Demonstrações Contábeis da Driving não foram corrigidas monetariamente?

O problema estava posto! Pelo pouco tempo de convívio com o novo gestor, Jorge sabia que a sua resposta possivelmente não o convenceria. Mas, enfim, nada restava senão dizer a verdade:

Sr. Antônio, em todo este período que estive aqui - e veja que falo desde a fundação desta empresa - fui orientado a concentrar todos os meus esforços nas questões de ordem fiscal e tributária. Na verdade, sempre fui cobrado, exclusivamente, neste aspecto! O meu antigo patrão trabalhava desta forma, sabe? Bom, o senhor 
também deve saber que existe, desde 1996, a proibição - para efeito fiscal - de se adotar esta prática. Então... Este é o motivo que nos levou - com a anuência e concordância - do antigo gestor - em não fazer a atualização monetária.

A discussão sobre estes aspectos durou pouco mais de 40 minutos. Antônio saiu da reunião convencido de duas coisas: que o seu "estilo" de gestão era demasiadamente diferente do antigo proprietário da Driving; e que, a equipe de contabilidade não foi suficientemente pró ativa para, pelo menos, propor ao gestor anterior a adoção do procedimento correto. E mais, de que era possível atualizar as Demonstrações Contábeis e se poder fazer os ajustes fiscais necessários.

Dado todo esse contexto, e de posse das informações recebidas do auditor - de que as Demonstrações não vinham sendo elaboradas com base nas práticas contábeis corretas - o empresário, convicto de que precisaria ser munido de informações fidedignas vê-se diante dos seguintes "dilemas": manter a equipe de contabilidade atual ou - considerando que está assumindo os rumos da empresa neste momento - substituir a equipe por outro (s) profissional (is)? A possível diferença de valores não reconhecidos influenciariam a tomada de decisão para a nova empresa?

\section{FONTE DE DADOS}

Este caso para ensino é fictício, portanto, os dados utilizados para a sua construção foram baseados em pesquisas realizadas em dissertações, artigos, livros e no conhecimento dos autores sobre os temas apresentados no caso.

\section{OBJETIVOS EDUCACIONAIS E UTILIZAÇÃO RECOMENDADA}

Este caso para ensino tem como objetivo discutir a importância da correção monetária, e o impacto causado nas demonstrações contábeis pela não atualização de valores monetários, bem como o reflexo disto no patrimônio das organizações e na tomada de decisão empresarial. O caso busca ainda propiciar uma discussão sobre questões relacionadas à demissão e contratação de funcionários.

O caso foi elaborado para utilização em cursos de graduação em Administração e Ciências Contábeis, em disciplinas de Contabilidade Societária, Análise das Demonstrações Contábeis e Administração Financeira.

\section{PLANO DE AULA}

Sugere-se que o professor peça aos alunos que façam a leitura prévia do caso e respondam as questões propostas antes da aula. No início da aula deve ser exposto aos acadêmicos os principais conceitos relacionados aos temas abordados no caso. Após a apresentação dos conceitos, os alunos devem reunir-se em pequenos grupos a fim de discutir as questões propostas. Posteriormente, as resoluções das questões devem ser expostas e debatidas no grande grupo, devendo o professor mediar as discussões em sala de aula. Para a aplicação do caso, propõe-se a seguinte distribuição de horário: 


\begin{tabular}{cc}
\hline Atividade & Duração (em minutos) \\
\hline Breve exposição dos conceitos & 25 \\
Organização da turma em pequenos grupos (até 4 alunos) & 5 \\
Discussão das questões em grupo & 30 \\
Discussão das questões no grande grupo & 60 \\
Fechamento das discussões e exposição das teorias apresentadas no caso & 25 \\
TOTAL & $\mathbf{1 4 5}$ \\
\hline
\end{tabular}

Quadro 3: Sugestão de Distribuição de Horário para Aplicação do Caso

Fonte: Elaborado pelos autores

\section{SUGESTÕES DE QUESTÕES PARA DISCUSSÃO}

1) Com base nas informações do caso, assuma o papel do Contador de Antônio Morais e faça a correção monetária, com base no IPCA, das Demonstrações Contábeis para os 5 anos apresentados.

2) Calcule os índices econômicos e financeiros das Demonstrações Contábeis com e sem correção referente aos 5 anos apresentados e faça uma análise comparativa. Além disto, comente quais índices não sofrem alterações com o impacto da correção monetária.

3) Em sua opinião, o Contador agiu corretamente ao desconsiderar a inflação na elaboração das Demonstrações Contábeis? Justifique sua resposta.

4) O índice utilizado para a correção das Demonstrações Contábeis foi o IPCA, por ser considerado o índice de inflação oficial utilizado pelo governo. Porém, outros indicadores poderiam ter sido utilizados. Pontue outras duas opções indicando qual a diferença entre elas.

5) Se você fosse Antônio Morais, diante de todas as informações evidenciadas, você manteria a equipe de contabilidade atual? Justifique sua resposta.

\section{ANÁLISE DO CASO}

\subsection{Correção Monetária de Balanços}

A Correção Monetária de Balanços, diferentemente da Correção Monetária Integral, somente incidirá sobre os Ativos Fixos (Investimentos, Imobilizado e Intangível) e também sobre o Patrimônio Líquido. Rezende (2009) enfatiza que a Correção Monetária sobre estes componentes do Balanço Patrimonial se justifica, pois são estes os que permanecem por mais tempo atrelados ao patrimônio e, portanto, estariam mais desatualizados. O autor ainda ressalta que a diferença desta correção (positiva para os itens do Ativo e negativa para os do Patrimônio Líquido), devem ser reconhecidos na Demonstração de Resultado para que se possa conhecer o lucro ou prejuízo efetivo da empresa.

Anteriormente, Oliveira, Marques e Canan (2007) já mencionavam que a Correção Monetária procura eliminar dos Balanços, distorções face à desatualização da expressão monetária do custo histórico, a subavaliação 
dos ativos não monetários e do Capital Próprio, à moeda da data do Balanço. Os autores complementam que a técnica consiste em um método de reconhecimento dos efeitos inflacionários nas Demonstrações Contábeis, aplicando-se um índice geral de preços com o objetivo de corrigir os valores dos Ativos Fixos (Investimentos, Imobilizado e Intangível) e do Patrimônio Líquido. A contrapartida das correções deve ser lançada em uma conta denominada “Correção Monetária” cujo saldo é transferido para o resultado como receita ou despesa.

Como a Correção Monetária de Balanços ocorre por conta da inflação, a mesma pode ser medida de várias formas. Sendo assim, Vieira, Arruda e Tavares (2016) afirmam que a inflação de cada país é medida por meio de indicadores que acompanham a variação de preços de determinados produtos, bens ou serviços e a partir dessa variação que é calculada a inflação, a taxa pelo qual os preços aumentam em determinado período de tempo. Para o trabalho em questão, foi utilizado o Índice de Preços ao Consumidor Amplo (IPCA), como adequado para medir os efeitos da inflação.

Diante disso, apresenta-se no Quadro 4, os Balanços Patrimoniais corrigidos.

\begin{tabular}{|c|c|c|c|c|c|}
\hline \multicolumn{6}{|c|}{ DRIVING COMÉRCIO DE VEÍCULOS LTDA } \\
\hline \multicolumn{6}{|c|}{ BALANÇOS PATRIMONIAIS CORRIGIDOS DOS ÚLTIMOS 5 ANOS (Em milhares de reais) } \\
\hline & 2015 & 2014 & 2013 & 2012 & 2011 \\
\hline ATIVO & 13.653 & 13.250 & 12.283 & 11.969 & 9.242 \\
\hline ATIVO CIRCULANTE & 9.654 & 9.260 & 9.329 & 10.465 & 7.992 \\
\hline CAIXA E EQUIVALENTES DE CAIXA & 5.780 & 5.459 & 7.278 & 5.098 & 4.954 \\
\hline CLIENTES & 2.644 & 2.785 & 975 & 4.321 & 2.355 \\
\hline OUTROS CRÉDITOS & 586 & 568 & 417 & 432 & 309 \\
\hline ESTOQUES & 610 & 388 & 558 & 585 & 358 \\
\hline DESPESAS PAGAS ANTECIPADAMENTE & 34 & 60 & 101 & 29 & 16 \\
\hline ATIVO NÃO CIRCULANTE & 3.999 & 3.990 & 2.954 & 1.504 & 1.250 \\
\hline IMOBILIZADO & 5.693 & 5.107 & 3.924 & 2.334 & 1.830 \\
\hline BENS EM OPERAÇÃO & 5.693 & 5.107 & 3.924 & 2.334 & 1.830 \\
\hline (-) DEPREC. E AMORT. ACUMULADAS & $(1.694)$ & $(1.117)$ & $(970)$ & $(830)$ & $(580)$ \\
\hline DEPRECIAÇÃO ACUMULADA & $(1.694)$ & $(1.117)$ & $(970)$ & $(830)$ & $(580)$ \\
\hline PASSIVO & 13.653 & 13.250 & 12.283 & 11.969 & 9.242 \\
\hline PASSIVO CIRCULANTE & 1.578 & 1.612 & 1.275 & 1.477 & 647 \\
\hline EMPRÉSTIMOS E FINANCIAMENTOS & - & 2 & 13 & 23 & 39 \\
\hline FORNECEDORES & 293 & 240 & 256 & 370 & 175 \\
\hline OBRIGAÇÕES TRABALHISTAS & 459 & 469 & 357 & 346 & 164 \\
\hline OBRIGAÇÕES FISCAIS & 821 & 896 & 642 & 730 & 265 \\
\hline OUTRAS OBRIGAÇÕES & 5 & 5 & 7 & 8 & 4 \\
\hline PATRIMÔNIO LÍQUIDO & 12.075 & 11.638 & 11.008 & 10.492 & 8.595 \\
\hline CAPITAL SOCIAL & 7.029 & 6.351 & 5.969 & 451 & 426 \\
\hline RESERVAS DE LUCRO & 5.046 & 5.287 & 5.039 & 10.041 & 8.169 \\
\hline
\end{tabular}

Quadro 4: Balanços Patrimoniais corrigidos

Fonte: Elaborado pelos autores

Em complemento, são evidenciadas no Quadro 5, as Demonstrações de Resultado corrigidas. 


\begin{tabular}{cccccc}
\hline \multicolumn{7}{c}{ DRIVING COMÉRCIO DE VEÍCULOS LTDA } \\
DEMONST. DE RESULTADO CORRIGIDAS DOS ÚLTIMOS 5 ANOS (Em milhares de Reais) \\
\hline (=) RECEITA OPERACIONAL LÍQUIDA & $\mathbf{2 0 1 5}$ & $\mathbf{2 0 1 4}$ & $\mathbf{2 0 1 3}$ & $\mathbf{2 0 1 2}$ & $\mathbf{2 0 1 1}$ \\
(-) CUSTOS DAS MERC. VENDIDAS & $(5.925$ & 11.024 & 9.044 & 14.050 & 8.624 \\
(=) LUCRO OPERACIONAL BRUTO & $\mathbf{2 . 8 2 9}$ & $(6.893)$ & $(5.599)$ & $(7.741)$ & $(5.136)$ \\
(-) DESPESAS/RECEITAS OPERACIONAIS & $(3.083)$ & $(3.854)$ & $(3.337)$ & $(3.908)$ & $(3.015)$ \\
(-) DESPESAS COMERCIAIS & $(1.356)$ & $(1.795)$ & $(1.495)$ & $(1.755)$ & $(1.306)$ \\
(-) DESPESAS ADMINISTRATIVAS & $(1.692)$ & $(1.998)$ & $(1.804)$ & $(2.086)$ & $(1.676)$ \\
(-) OUTRAS DESPESAS OPERACIONAIS & $(43)$ & $(76)$ & $(57)$ & $(93)$ & $(35)$ \\
(+) OUTRAS RECEITAS OPERACIONAIS & 8 & 15 & 19 & 26 & 2 \\
(=) RESULTADO ANTES DO RESULTADO & $\mathbf{( 2 5 4 )}$ & $\mathbf{2 7 7}$ & $\mathbf{1 0 8}$ & $\mathbf{2 . 4 0 1}$ & $\mathbf{4 7 3}$ \\
FINANCEIRO & $(93)$ & $(46)$ & $(19)$ & $(23)$ & $(13)$ \\
(-) DESPESAS FINANCEIRAS & 527 & 505 & 597 & 678 & 307 \\
(+) RECEITAS FINANCEIRAS & $(1.211)$ & $(507)$ & $(418)$ & $(665)$ & $(477)$ \\
$(-)$ DESPESA COM CORREÇÃO MONETÁRIA & $(\mathbf{3 . 4 4 5})$ \\
(=) RESULTADO ANTES DOS TRIBUTOS & $\mathbf{( 1 . 0 3 1 )}$ & $\mathbf{2 2 9}$ & $\mathbf{2 6 8}$ & $\mathbf{2 . 3 9 1}$ & $\mathbf{2 9 0}$ \\
SOBRE O LUCRO & $(49)$ & $(238)$ & $(221)$ & $(1.027)$ & $(249)$ \\
(-) TRIBUTOS SOBRE O LUCRO & $\mathbf{( 1 . 0 8 0 )}$ & $\mathbf{( 9 )}$ & $\mathbf{4 7}$ & $\mathbf{1 . 3 6 4}$ & $\mathbf{4 1}$ \\
\hline
\end{tabular}

Quadro 5: Demonstrações de Resultado corrigidas

Fonte: Elaborado pelos autores

Diante das Demonstrações Contábeis corrigidas, pode-se perceber que o patrimônio da empresa em 2015 teve um aumento de $9,23 \%$ (de $\mathrm{R} \$ 12.499 .000,00$ para $\mathrm{R} \$ 13.653 .000,00$ ), o que representa um incremento de $\mathrm{R} \$$ 1.154.000,00 por meio da correção monetária decorrente da inflação. Também é importante ressaltar que como o Patrimônio Líquido possui valores superiores ao do Ativo Imobilizado, a diferença decorrente deste ajuste resultou em uma despesa com correção monetária, o que incidiu diretamente na redução do lucro da empresa e que como esta despesa não é dedutível para fins fiscais, os tributos sobre o lucro continuam iguais.

\section{2 Índices econômicos e financeiros}

Não considerar o efeito inflacionário nas Demonstrações Contábeis pode afetar consideravelmente o resultado da empresa. Dessa forma, Ambrozini (2006) menciona que a desconsideração de efeitos inflacionários nas Demonstrações Contábeis é capaz de provocar alteração no resultado apurado em determinado período, quando comparado às Demonstrações Contábeis corrigidas. Dessa forma, há a possibilidade de alteração de uma série de importantes indicadores muito utilizados para se analisar as empresas, entre eles, a rentabilidade do Patrimônio Líquido.

Oliveira, Marques e Canan (2007) complementam que se não considerada a inflação nas Demonstrações Contábeis, além de causar grandes perdas na qualidade da informação prestada pela contabilidade, pode alterar significativamente o resultado apurado pelas empresas e, como consequência, a distorção da decisão quanto à distribuição de lucros. Diante disso, apresenta-se na Tabela 2, o cálculo dos índices financeiros e econômicos para as Demonstrações Contábeis com e sem inflação, que foram baseados no autor Matarazzo (2010). 
Tabela 2. Cálculo dos índices financeiros e econômicos

\begin{tabular}{|c|c|c|c|c|c|}
\hline Índice & 2011 & 2012 & 2013 & 2014 & 2015 \\
\hline \multicolumn{6}{|l|}{ Participação de CT } \\
\hline Sem correção & $7,59 \%$ & $14,31 \%$ & $12,11 \%$ & $14,94 \%$ & $14,45 \%$ \\
\hline Com Correção & $7,53 \%$ & $14,08 \%$ & $11,58 \%$ & $13,85 \%$ & $13,07 \%$ \\
\hline \multicolumn{6}{|l|}{ Imobilização do PL } \\
\hline Sem correção & $13,78 \%$ & $12,93 \%$ & $23,50 \%$ & $29,12 \%$ & $26,05 \%$ \\
\hline Com Correção & $14,54 \%$ & $14,33 \%$ & $26,84 \%$ & $34,28 \%$ & $33,12 \%$ \\
\hline \multicolumn{6}{|c|}{$\begin{array}{l}\text { Imob. de Recursos Não } \\
\text { Correntes }\end{array}$} \\
\hline Sem correção & $13,78 \%$ & $12,93 \%$ & $23,50 \%$ & $29,12 \%$ & $26,05 \%$ \\
\hline Com Correção & $14,54 \%$ & $14,33 \%$ & $26,84 \%$ & $34,28 \%$ & $33,12 \%$ \\
\hline \multicolumn{6}{|l|}{ Giro do Ativo } \\
\hline Sem correção & 0,94 & 1,19 & 0,77 & 0,89 & 0,63 \\
\hline Com Correção & 0,93 & 1,17 & 0,74 & 0,83 & 0,58 \\
\hline \multicolumn{6}{|l|}{ Margem Líquida } \\
\hline Sem correção & $6,01 \%$ & $14,44 \%$ & $5,14 \%$ & $4,52 \%$ & $1,65 \%$ \\
\hline Com Correção & $0,48 \%$ & $9,71 \%$ & $0,52 \%$ & $-0,08 \%$ & $-13,63 \%$ \\
\hline \multicolumn{6}{|c|}{ Rentabilidade do Ativo } \\
\hline Sem correção & $5,65 \%$ & $17,19 \%$ & $3,94 \%$ & $4,02 \%$ & $1,05 \%$ \\
\hline Com Correção & $0,44 \%$ & $11,40 \%$ & $0,38 \%$ & $-0,07 \%$ & $-7,91 \%$ \\
\hline \multicolumn{6}{|l|}{ Rentabilidade do PL } \\
\hline Sem Correção & $6,09 \%$ & $19,66 \%$ & $4,42 \%$ & $4,61 \%$ & $1,20 \%$ \\
\hline Com Correção & $0,48 \%$ & $13,00 \%$ & $0,43 \%$ & $-0,08 \%$ & $-8,94 \%$ \\
\hline
\end{tabular}

Fonte: Elaborado pelos autores (2016)

Ao analisar os índices de estrutura de capital (Participação de Capitais de Terceiros, Imobilização do PL e Imobilização de Recursos Não Correntes), que são classificados como índices financeiros, em ambos os casos são considerados bons, pois percebe-se que a empresa não apresenta dependência a terceiros e também não utilizou recursos de terceiros para financiar o Ativo Não Circulante.

É oportuno lembrar que o índice de Participação de Capitais de terceiros reduziu nas demonstrações corrigidas pois enquanto o capital de terceiros manteve-se constante, o Patrimônio Líquido aumentou. Em relação aos índices de Imobilização do PL e Imobilização de Recursos Não Correntes são os mesmos, visto que a empresa analisada não possui o grupo de contas Passivo Exigível a Longo Prazo. Já os índices aumentaram nas demonstrações corrigidas por conta de o Ativo Não Circulante ter aumentado mais que o Patrimônio Líquido.

No que tange os índices de rentabilidade (Giro do Ativo, Margem Líquida, Rentabilidade do Ativo e Rentabilidade do PL), percebe-se que como a Correção Monetária resultou em uma despesa, a mesma incidiu diretamente na queda do lucro. Nos anos de 2014 e 2015 esta queda torna-se ainda mais evidente, visto que a empresa passa de uma situação superavitária, para uma situação deficitária e que assim, poderia refletir diretamente em uma possível decisão de distribuição de lucros.

O Ativo somente é totalmente utilizado na geração de vendas líquidas no ano de 2012, e as vendas, a empresa gera lucratividade e o capital próprio obteve rendimentos, com exceção dos índices das demonstrações corrigidas em 2014 e 2015.

Todos os índices de rentabilidade reduziram nas demonstrações corrigidas, em decorrência da queda do 
lucro, motivado pela despesa com correção monetária. Com relação à viabilidade do negócio, o mesmo após a correção não apresenta um bom retorno, visto que com exceção do ano de 2012, a empresa retorna aos seus sócios um percentual abaixo de $0,50 \%$ ao ano, o que, se for comparado à poupança (investimento com risco baixo), há um retorno de aproximadamente de $6 \%$ a $7 \%$ no ano.

Ressalta-se que o índice de Composição do Endividamento (financeiro) e os índices de liquidez (Liquidez Geral, Liquidez Corrente e Liquidez Seca) não sofreram alterações com o impacto da correção monetária, uma vez que em suas fórmulas de cálculo não estão incluídos o Ativo Não Circulante ou o Patrimônio Líquido.

\subsection{Legislação para aplicação da correção monetária}

A Correção Monetária foi introduzida de forma facultativa no ano de 1944, por meio do Decreto-Lei $\mathrm{n}^{\circ}$ 5.844 e passou a ser obrigatória em 1964, por meio da Lei $n^{\circ} 4.357$ (TAKAMATSU e LAMOUNIER, 2006). Em complemento, Ambrozini, Bonacim e Assaf Neto (2008) enfatizam que a Lei $n^{\circ}$ 6.404/1976 tornou obrigatória a Correção Monetária das Demonstrações Contábeis para todas as empresas brasileiras de capital aberto. Já no ano de 1977, com o Decreto-Lei ${ }^{\circ} 1.598$, o fisco determinou por meio da legislação do Imposto de Renda que todas as empresas tributadas pelo lucro real também estavam obrigadas a efetuar a Correção Monetária em suas Demonstrações Contábeis.

No ano de 1995, por meio da Lei n ${ }^{0}$ 9.249, foi revogada a Correção Monetária das Demonstrações Contábeis, proibindo a utilização de qualquer técnica, inclusive para fins societários (MONTEIRO e MARQUES, 2006). No entanto, Ambrozini, Bonacim e Assaf Neto (2008) explicam que a partir do ano de 1996, a publicação de Demonstrações Contábeis corrigidas passou a ser facultativa. Enquanto a Comissão de Valores Mobiliários (CVM) advertiu as empresas sob sua supervisão da importância da elaboração e divulgação de Demonstrações Contábeis relevantes para todos os usuários da contabilidade. Dessa forma, as empresas que desejassem aplicar a correção monetária deveriam evidenciá-la em nota explicativa.

Dando ênfase à legislação contábil, o Conselho Federal de Contabilidade (CFC) por meio da Resolução ${ }^{\circ}$ 750/1993 definiu que um dos Princípios Contábeis a serem aplicados na escrituração contábil era o da "Atualização Monetária", na qual mencionava que os efeitos da alteração do poder aquisitivo da moeda do país devem ser reconhecidos nas Demonstrações Contábeis por meio do ajuste da expressão formal dos componentes patrimoniais (CONSELHO FEDERAL DE CONTABILIDADE, 1993).

Entretanto, no ano de 2001, o CFC publicou a Resolução $n^{0}$ 900, que explicava como deveria ser feita a aplicação do Princípio da Atualização Monetária, enfatizando que a aplicação deste Princípio só seria obrigatório caso a inflação acumulada no triênio fosse superior a 100\% (CONSELHO FEDERAL DE CONTABILIDADE, 2001).

No ano de 2010, a Resolução $n^{\circ} 1.282$ extinguiu o Princípio da Atualização Monetária e revogou a Resolução $n^{\circ}$ 900/2001. Entretanto a mesma Resolução previa, dentro de outro Princípio (o do Registro Pelo Valor Original) a Atualização Monetária, afirmando que os efeitos da alteração do poder aquisitivo da moeda do país devem ser reconhecidos nas Demonstrações Contábeis mediante o ajustamento da expressão formal dos valores dos componentes patrimoniais (CONSELHO FEDERAL DE CONTABILIDADE, 2010).

Também revogada a citada Resolução (1.282), cumpre destacar que a NBC TG que versa sobre a Estrutura Conceitual para elaboração e apresentação das Demonstrações Contábeis (Resolução CFC n ${ }^{\circ}$ 1.374/11) ainda indica que uma das características qualitativas fundamentais da informação contábil financeira envolve, justamente, a necessidade de sua representação fidedigna.

Para o caso em questão, se pode adotar duas vertentes para responder ao questionamento. Primeiro, o aluno pode basear-se na premissa de que a partir do ano de 1996, a correção das Demonstrações Contábeis passou a ser facultativa, o que dessa forma, dá direito de escolha de fazer ou não. Por outro lado, o aluno pode seguir o que alerta a CVM e a NBC TG Estrutura Conceitual, afirmando que as Demonstrações Contábeis devem representar informações relevantes e fidedignas, não podendo a inflação ser ignorada.

\subsection{Indicadores de inflação}


No que diz respeito ao indicador de inflação, este é medido por meio de diversos índices, divulgados por várias instituições (BACEN, 2016). No que tange às possibilidades de indicadores para correção, o Quadro 6 apresenta uma síntese das mesmas. Vale ressaltar que existem também índices setoriais calculados pela FGV (2017), porém estes são coletados mediante solicitação e não estão disponíveis com amplo acesso.

\begin{tabular}{|c|c|c|c|c|}
\hline Indicador & $\begin{array}{c}\text { BACEN } \\
(2017)\end{array}$ & $\begin{array}{l}\text { IBGE } \\
(2017)\end{array}$ & $\begin{array}{l}\text { FGV } \\
(2017)\end{array}$ & Síntese do Indicador \\
\hline INPC & $X$ & $\mathrm{X}$ & & $\begin{array}{l}\text { Índice Nacional de Preço - mede a variação do custo de vida das } \\
\text { famílias com rendimentos entre } 1 \text { e } 5 \text { salários mínimos. }\end{array}$ \\
\hline IPC & $\mathrm{X}$ & $\mathrm{X}$ & $\mathrm{X}$ & $\begin{array}{l}\text { Índice de Preços ao Consumidor. Existem algumas variações } \\
\text { no seu cálculo, porém a lógica é a mesma. Medir a variação do } \\
\text { custo de vida das famílias com rendimento entre } 1 \text { e } 40 \text { salários. } \\
\text { Variações: IPCA - Consumidor Amplo (indicador oficial de } \\
\text { inflação); IPCA-15 (finalizado no dia } 15 \text { de cada mês); IPC-3I } \\
\text { - Índice de Preços ao Consumidor da Terceira Idade; IPC-C1 - } \\
\text { Índice de Preços ao Consumidor ao Consumidor Classe } 1 \text { (com } \\
\text { renda entre } 1 \text { e } 2,5 \text { salários mínimos), IPC-S - Semanal; IPC- } \\
\text { Fipe - Índice de Preços ao Consumidor na cidade de São Paulo. }\end{array}$ \\
\hline IGP & $\mathrm{X}$ & & $\mathrm{X}$ & $\begin{array}{l}\text { Índice Geral de Preços é a média aritmética dos índices IPA, IPC } \\
\text { e INCC; respectivamente Índice de Preços ao Produtor Amplo; } \\
\text { Índice de Preços ao Consumidor e Índice Nacional de Custo da } \\
\text { Construção. Comumente utilizado como indexador de contratos } \\
\text { e deflator monetário. } \\
\text { Variações: IGP-DI - Índice Geral de Preços - Disponibilidade } \\
\text { Interna (coleta de } 1 \text { a } 31 \text { do mês analisado); IGP-M - Preços de } \\
\text { Mercado ( } 21 \text { a 20); IGP-10 (11 a 10). }\end{array}$ \\
\hline IPA & & & $\mathrm{X}$ & $\begin{array}{l}\text { Índice de Preços por Atacado - analisa produtos agrícolas e } \\
\text { industriais. }\end{array}$ \\
\hline INCC & & & $\mathrm{X}$ & Índice Nacional da Construção Civil. \\
\hline
\end{tabular}

Quadro 6: Síntese dos Indicadores Gerais de Preços

Fonte: BACEN (2017); IBGE (2017); FGV (2017)

Com base nos indicadores anteriormente citados, também seria possível realizar a correção com os indicadores: INPC e IGP.

\subsection{Resolução do caso}

É importante destacar que este caso para ensino não possui resposta certa ou errada, existem, porém, algumas decisões que devem ser tomadas pelo novo proprietário da Driving, Antônio Morais.

Diante da descoberta dos equívocos cometidos pelo departamento contábil da empresa na elaboração das Demonstrações Contábeis, recai sobre Antônio a responsabilidade de decidir se mantém a atual equipe de contabilidade ou substitui a mesma por novos profissionais. A decisão de Antônio deve ser pautada não somente na situação atual da Driving, mas, também em todo histórico empresarial desses 18 anos de existência da organização.

Para tomar essa decisão, não é possível desconsiderar todo conhecimento que o Contador responsável detém sobre a empresa, uma vez que, este funcionário trabalha nela desde a sua fundação. Será ele - talvez - o funcionário que mais poderá auxiliar e aconselhar Antônio, nesse início de gestão na empresa que é - até então nova para ele.

O impacto da demissão do departamento contábil pode refletir de maneira negativa, não só nas operações da empresa devido à adaptação, integração e a falta de conhecimento da nova equipe que irá assumir o setor, mas também, no clima organizacional, tendo em vista a insegurança que esta atitude trará para os funcionários dos outros setores da organização. 
Uma mudança de gestão geralmente abala os colaboradores da empresa, conforme afirma Bertulucci (2006), mudanças trazem reações, pois o novo gera expectativas, que podem ser positivas e/ou negativas. O fato de não se saber sobre os próximos acontecimentos e decisões, ocasiona sentimentos de diversas naturezas. No caso da Driving, uma demissão de um setor inteiro realizada pelo novo gestor, pode fazer com que os funcionários fiquem inseguros e receosos com a nova administração. A perda do emprego por meio da demissão é algo significativo na vida das pessoas, pois está simbolicamente associada ao fracasso pessoal, muito embora algumas situações não sejam consequências do fracasso individual, ainda assim elas geram insegurança no indivíduo (CALDAS, 2000).

Outro ponto a ser analisado pelo novo gestor, trata-se das decisões a serem tomadas a partir dos novos valores de patrimônio apresentados a ele. A realidade patrimonial que lhe foi demonstrada no momento da aquisição da Driving não condiz com a realidade retratada após os ajustes contábeis realizados, portanto, cabe a Antônio buscar estratégias junto a seus colaboradores para tornar a empresa lucrativa e rentável.

Por outro lado, é necessário que Antônio pese em sua decisão os erros cometidos pelo atual setor de contabilidade, considerando a relação de confiança que deve existir entre as partes (gestor e setor contábil) para que o desempenho da empresa seja satisfatório. Há de se refletir, ainda, a respeito da percepção de Antônio quanto à falta de pró atividade da equipe em propor ao antigo gestor a adoção do procedimento correto quanto à atualização monetária dos valores registrados no patrimônio. É importante considerar também que o fato da empresa estar sob uma nova gestão pode mudar o desempenho do setor, bem como a cultura empresarial que está embutida nos mesmos.

A cultura organizacional é uma dimensão de caráter dinâmico, e que é revelada por meio de expressões próprias de cada empresa, como regras, normas e rotinas que servem como guia aos comportamentos humanos e agem como elemento de comunicação e consenso (SCHADECK et al, 2016). Dessa forma, Antônio deve considerar em sua decisão, a possível mudança de comportamento dos funcionários a partir do estabelecimento de uma nova gestão empresarial. É importante que ele avalie os prós e contras em se tentar modificar toda uma cultura já posta há mais de 18 anos, porém, esse processo de mudança pode ser no momento a melhor opção para o novo proprietário da empresa, e um caminho para o sucesso da Driving.

\section{BIBLIOGRAFIA UTILIZADA E RECOMENDADA}

AMBROZINI, M. A. O impacto do fim da correção monetária no resultado das companhias brasileiras de capital aberto e na distribuição de dividendos: estudo empírico no período de 1996 a 2004. 2006. 188f. Dissertação (Mestrado em Controladoria e Contabilidade) - Programa de Pós-Graduação em Controladoria e Contabilidade, Universidade de São Paulo, Ribeirão Preto, 2006.

AMBROZINI, M. A.; BONACIM, C. A. G.; ASSAF NETO, A. O impacto do fim da correção monetária no resultado das companhias brasileiras de capital aberto e na distribuição de dividendos: Estudo Empírico no Período Pós-Plano Real. Qualitas Revista Eletrônica, v. 7, n. 2, 2008.

BANCO CENTRAL DO BRASIL (BACEN). Índices de Inflação. 2016. Disponível em:<http://www.bcb.gov.br/ pre/portalCidadao/indecon/indice inflacao.asp?idPai=PORTALBCB>. Acesso em: 04 abr. 2016.

BANCO CENTRAL DO BRASIL (BACEN). Índices Econômicos Consolidados. 2017. Disponível em: < http:// www.bcb.gov.br/pec/Indeco/Port/indeco.asp>. Acesso em: 03 jan. 2017.

BERTULUCCI, C. R. Impactos emocionais causados pela mudança de estilo de gestão em um hospital na cidade de São Luis-MA. 111f. Dissertação (Mestrado em Gestão Empresarial) - Escola Brasileira de Administração Pública de Empresas, Fundação Getúlio Vargas, Rio de Janeiro, 2006.

CALDAS, M.P. Demissão: Causas, efeitos e alternativas para empresa e indivíduo. São Paulo: Atlas, 2000.

CONSELHO FEDERAL DE CONTABILIDADE. Resolução CFC n ${ }^{0}$ 750/93. Dispõe sobre os Princípios Fundamentais de Contabilidade (PFC). Disponível em: <www.cfc.org.br/sisweb/sre/docs/RES_750.doc >. Acesso em: 08 abr. 2016.

CONSELHO FEDERAL DE CONTABILIDADE. Resolução CFC ñ 900/01. Dispõe sobre a aplicação do Princípio da Atualização Monetária. Disponível em: <www.cfc.org.br/sisweb/sre/docs/RES_900.doc>. Acesso em: 08 abr. 2016. 
CONSELHO FEDERAL DE CONTABILIDADE. Resolução CFC n ${ }^{0} 1.282 / 10$. Atualiza e consolida dispositivos da Resolução CFC n 750/93, que dispõe sobre os Princípios Fundamentais de Contabilidade. Disponível em: <www.cfc.org.br/sisweb/sre/docs/RES_1282.doc>. Acesso em: 08 abr. 2016.

CONSELHO FEDERAL DE CONTABILIDADE. Resolução CFC no 1.374/11. Dá nova redação à NBC TG Estrutura Conceitual - Estrutura Conceitual para Elaboração e Divulgação de Relatório Cont-abilFinanceiro. Disponível em: <www.cfc.org.br/sisweb/sre/docs/RES_1374.doc>. Acesso em: 03 jan. 2017.

FUNDAÇÃO GETÚLIO VARGAS (FGV). Indicadores de Preços. 2017. Disponível em:<http://portalibre.fgv. br/main.jsp?lumChannelId=402880811D8E34B9011D92AF56810C57>. Acesso em: 03 jan. 2017.

INSTITUTO BRASILEIRO DE GEOGRAFIA E ESTATÍSTICA (IBGE). Índices de Preços ao Consumidor. 2017. Disponível em: <http://www.ibge.gov.br/home/estatistica/indicadores/precos/inpc_ipca/defaulttab. shtm>. Acesso em: 03 jan. 2017.

MATARAZZO, D. C. Análise Financeira de Balanços: Abordagem Gerencial. 7 ed. São Paulo: Atlas, 2010.

MONTEIRO, P. R. A.; MARQUES, J. A. V. C. Análise comparativa das demonstrações contábeis elaboradas pela legislação societária e em moeda constante: um estudo de caso. Revista de Contabilidade do Mestrado em Ciências Contábeis da UERJ, v. 11, n. 1, 2006.

OLIVEIRA, A. T.; MARQUES, J. A. V. C.; CANAN, I. 11 anos sem correção! Uma análise dos efeitos da correção monetária não reconhecida nas Demonstrações Contábeis do Serviço Social da Indústria - SESI de 1996 a 2006. Revista de Contabilidade do Mestrado em Ciências Contábeis da UERJ, v. 12, n. 3, 2007.

REZENDE, A. J. Um estudo sobre o processo de desinstitucionalização das práticas contábeis de correção monetária em empresas brasileiras. 2009. 267f. Tese (Doutorado em Ciências Contábeis) - Programa de Pós-Graduação em Ciências Contábeis, Universidade de São Paulo, São Paulo, 2009.

SCHADECK, M. et al. Cultura organizacional e os sete pecados capitais: uma proposta para compreender os sistemas simbólicos. Cadernos EBAPE.BR, v. 14, n. 1, p. 164-181, 2016.

TAKAMATSU, R. T.; LAMOUNIER, W. M. A importância da atualização monetária de valores para a análise das demonstrações financeiras. Contabilidade Vista \& Revista, v. 17, n. 2, p. 67-87, 2006.

VIEIRA, C. A. M.; ARRUDA, M. P.; TAVARES, A. L. O impacto da inflação no endividamento das instituições financeiras brasileiras. Revista de Gestão, Finanças e Contabilidade, v. 6, n. 1, p. 28-44, 2016. 